\title{
Essência e Aparência na Organização da Produção e do Trabalho das Fábricas "Reestruturadas"
}

\section{Mario Sergio Salerno}

\author{
Professor-Doutor \\ Escola Politécnica da USP \\ Departamento de Engenharia de Produção \\ CP 8174 01065-970 São Paulo - SP \\ tel.(011)8185192 r.464 / 8185363 fax. (011)8147496 \\ email-internet:msalerno@usp.br
}

Palavras-chave: reestruturação produtiva, mudança organizacional, trabalho em grupo

Key words: production restructuring, organisational change, group work

\section{RESUMO}

O texto discute a mudança organizacional na produção das empresas industriais contemporâneas a partir de uma visão particular do que seria o âmago da abordagem clássica de organização, qual seja, o conceito de "tarefa". É discutido um caso de mudança radical de organização do trabalho numa empresa radicada no Brasil, que exemplifica bem a ruptura do "paradigma"de tarefa.

\section{ABSTRACT}

The paper discusses organisational change in industry based on a special interpretation of the classical approach of organisation theory: the "task" concept. A case of radical work organisation change in an industrial company in Brazil is analysed; the case shows a rupture of the "task paradigm". 


\section{Introdução}

São diversas as caracterizações sobre o processo de globalização da economia, bem como são diversas as formas que o processo assume, conforme as características históricas, sociais, institucionais, sindicais e de políticas públicas praticadas pelos diversos estados nacionais/regiões. Neste texto, procuraremos o recorte das mudanças na produção industrial, no processo que vem sendo chamado de reestruturação produtiva. Analisaremos a empresa e o trabalho industrial, e sua organização. Tentaremos, pois, "entrar" dentro do espaço fabril e discutir tendências de mudanças lá percebidas.

É curioso como a fábrica é algo "opaco" para a maioria das pessoas; pouco se conhece do que ali se passa, de como os produtos são feitos, de como se trabalha na produção material. Talvez isso seja reflexo, por um lado, de relações de trabalho não caracterizadas pela organização dos trabalhadores nos locais de trabalho, mas, por outro, parece revelar um certo desprezo frente ao trabalho produtivo direto, símbolo do abismo existente entre as diversas classes sociais no Brasil.

Convém caracterizarmos brevemente as mudanças em curso, para delimitarmos o campo de abrangência da análise.

\section{Caract erização da Reestruturação Produtiva}

Uma empresa estabelece implícita ou explicitamente sua estratégia de negócios (quais produtos, para quais mercados, e em qual volume) de acordo com sua percepção do ambiente. Definida a estratégia de negócios, passa-se à estratégia de produção, ou seja, quais as necessidades de infra-estrutura e organização para viabilizar a estratégia de negócios.

Como houve uma forte mudança no ambiente, internacionalmente a partir do início dos anos 70 , e no Brasil, principalmente no início dos anos 90, as empresas procuraram rever suas estruturas, visando adequá-las às novas estratégias.

Consideramos que a reestruturação produtiva está intimamente ligada à busca de flexibilidade (para fazer frente a situações não muito previsíveis social e economicamente, e para diferenciação frente à concorrência, se possível lançando novos produtos para ampliar os horizontes dos mercados tradicionais) e de integração dos fluxos materiais e informacionais, como forma de dar saltos de produtividade sem depender excessivamente da escala produtiva (o que não pode ser tomado como regra geral de competição intercapitalista, mas que tem sua importância relativa aumentada), e de atuar com estruturas organizacionais mais planas, mais ágeis, menos "inchadas".

Tomado de outra forma, no âmbito de uma determinada firma, parece tratar-se antes de uma questão de economia de capital $^{1}$, do que de economia de trabalho, ainda que muitas vezes esta última seja a mais visível. A incerteza desestimula a concentração de investimento num só negócio, ou numa só fábrica, induzindo à horizontalização. Os altos juros geram 
custos de oportunidade elevados relativos à manutenção de estoques e ao baixo giro do capital. A diferenciação via lançamento de novos produtos, qualidade, rapidez na entrega e nível de serviço associado a um produto fabril se adiciona às tradicionais ações para redução de custos.

O fator tempo sobe ao primeiro plano. Aproveitar oportunidades de mercado - e se possivel, criá-las - é um dos fatores básicos da lucratividade. Para isso é preciso uma agilidade muito grande na estrutura, que vai desde o projeto do produto até a comercialização e assistência técnica, passando pela fabricação, relação com fornecedores.

Para buscar esses objetivos, as empresas introduzem inovações tecnológicas e organizacionais.

As inovações tecnológicas são mais visíveis: informática e automação, biotecnologia, novos materiais, novos processos de transformação etc. Porém, a lógica do funcionamento da empresa reestruturada é definida não pelo equipamento, mas pela organização: é isso, por exemplo, que explica o fato de a GM ter investido alguns bilhões de dólares em automação nos EUA sem obter o sucesso esperado. Fazendo algumas analogias, a história militar parece pródiga em exemplos de como a organização pode levar a uma "vantagem competitiva": exemplos típicos são a "falange" de Alexandre, o grande, e a organização dos exércitos romanos e da guerrilha vietnamita, que conseguiam vencer batalhas frente a exércitos muito mais numerosos ou equipados ${ }^{2}$.

A ơrganização pode ser entendida como um "amálgama" que liga questões técnicas (relação homem-materiais), sociais (relação entre homens, envolvendo não só questões como hierarquia, poder, coordenação de conflitos, mas também questões cognitivas e de comunicação intersubjetiva) e econômicas, tudo em função de uma estratégia.

A novidade no campo organizacional é a difusão da passagem de uma estrutura por "funções" para uma estrutura por "processo": no lugar do departamento de tornos, do departamento de fresas, do departamento de retíficas, células de produção que produzem, do começo ao fim, um determinado conjunto de peças semelhantes; no lugar da diretoria de produção, da diretoria de manutenção, da diretoria de qualidade, uma diretoria de operação que tem como objetivo produzir produtos, sendo responsável pela manutenção e qualidade (que são serviços prestados à atividade fim); no lugar de um operador de máquina, um inspetor de qualidade, um preparador, operários "polivalentes".

É certo que essa mudança não nasce nos anos 60,70 ou 80. Da mesma forma como a organização clássica não surge exclusivamente do gênio de Frederick Taylor ou Henri Fayol, tendo suas raízes já descritas por Adam Smith ao analisar a hoje famosa fábrica de alfinetes, as formas alternativas à organização clássica vem se constituindo há um certo tempo. Ocorre, porém, que mais recentemente 
consolidaram-se as condições econômicas, sociais, técnicas e políticas para a aceleração de sua difusão, na indústria e nos serviços.

Há muitas análises sobre o "novo" na reestruturação produtiva, sobre a ruptura de padrões clássicos, geralmente chamados de "taylorismo". Para precisarmos nossa análise, faz-se necessário nos posicionarmos frente a esse debate, que é bastante complexo. Nesse sentido, a caracterização de taylorismo que nos parece mais interessante é aquela proposta por Philippe Zarifian (1990).

Em linhas gerais, a grande contribuição da proposta taylorista foi o conceito de tarefa $^{3 .} \mathrm{O}$ grande problema na virada do século era o aumento do volume de produção, o aumento da taxa de produção por trabalhador (ou produtividade física, se quiserem). Em sistemas de produção onde o peso da mão-de-obra é bastante grande, $\mathrm{e}$ onde o volume de produção depende do volume de mão-de-obra, tal aumento de produção vai depender do aumento da velocidade de execução do trabalho. $O$ sistema de tarefa vem solucionar tal problema: uma equipe externa à produção projeta e atribui para cada trabalhador um conjunto de instruções, de sequiência de movimentos, que deve ser desempenhado num dado posto de trabalho, que é projetado conjuntamente com o projeto dos movimentos operários. $\mathrm{O}$ trabalho é tratado objetivadamente, ou seja, independentemente de seu executante. $O$ critério de eficiência é o tempo da operação, que faz parte da noção de tarefa.
Tal concepção é ao mesmo tempo bastante simples e poderosa, pois consegue aliar, num único e relativamente objetivo critério - o tempo associado a cada operação - tanto as questões de planejamento físico da produção (processo de trabalho, por assim dizer) quanto as questões de economia da produção (valorização). $O$ tempo é o critério para projeto do trabalho, balanceamento de linhas, estudo de carga de trabalho etc, mas também é o insumo básico para estudar a relação entre o operário e a maquinaria, e para integrar os custos de produção na lógica da contabilidade analítica. $O$ custo de um produto tem relação direta com o número de homens-hora alocados, e com o número de horas-máquina; o planejamento econômico pode ser feito com base da estimação de tempo, e assim por diante.

A empresa é subdividida em departamentos funcionais (Fayol), e a produção é subdividida em operações/postos consoante o conceito de tarefa (Taylor).

Tal' é hoje banal para profissionais de gestão da produção (administradores, contadores, economistas, engenheiros etc.), mas é uma construção histórica determinada ${ }^{4}$, que se consolidou ao longo desse século. E que entra em crise relativa agora neste final de século.

A crise é relativa porque: 1) por um lado, há um processo de mudança na abordagem da tarefa, sem contestá-la frontalmente; 2) por outro, há um processo de contestação da tarefa, via uma organização menos prescritiva e mais 
"aberta". Se tiramos hoje uma fotografia das fábricas que estão se "reestruturando", notaremos a ocorrência dos dois casos.

\section{A Reestruturação à Luz do Conceito de Tarefa: Essência e Aparência}

O que vem sendo chamado de mudança organizacional é um conjunto não homogêneo, e muitas vezes contraditório, de alterações na empresa e, por assim dizer, no sistema de empresas - a noção de "consórcio modular" ou "condomínio industrial" que está na raiz da concepção da fábrica de caminhões da VW em Resende ${ }^{5}$, significa um grande passo rumo ao negócio industrial virtual: a VW pouco produz diretamente, mas projeta, coordena, comercializa e assina embaixo, garantindo uma participação no mercado com um investimento menor. Mas vamos para dentro das fábricas.

Tomando o conceito de organização clássica esboçado acima (ou de "taylorismo", mais simplificadamente) como critério metodológico de classificação, podemos verificar algumas direções dessa mudança, direções que coexistem, e, numa primeira análise, coexistirão por longo tempo.

\section{Mudanças que não contestam o} conceito de tarefa

Configuram-se enquanto adaptações do modelo clássico de tarefa, sem questionar sua essência. É o caso de programas tipo enriquecimento de cargos, polivalência no sentido de multitarefa, trabalho dito em grupo numa linha de montagem ${ }^{6}$, programas de qualidade tomados isoladamente (especialmente esquemas tipo 5S, housekeeping, controle estatístico de processo se o operário só colhe amostras de dados, mas não analisa gráficos e não interfere no processo com o fim de reajustá-lo etc). É certo que o trabalho da pessoa muda, mas a essência da abordagem organizacional, do projeto organizacional, permanece intocado: um corpo externo à produção continua projetando a tarefa a ser atribuída ao operário, só que agora essa tarefa engloba limpeza da área, realização de lubrificação da máquina a cada $\mathrm{x}$ horas, operação de várias máquinas etc, tudo conforme o roteiro prescrito pelos serviços de engenharia/métodos.

Classificamos aqui inclusive esquemas que "facultam" ao operário a mudança de método. Ora, se há uma linha de montagem, se as pessoas estão alocadas naquele posto (ou conjunto de postos), se as sugestões de mudanças são analisadas por equipe especializada, se a implantação da mudança pode afetar outros operários que não a sugeriram ... parece ocorrer apenas um pequeno deslocamento vertical de atribuições. Tomando as pesquisas de Koichi Shimizu (1994) sobre o kaizen na Toyota japonesa, podemos pensar que muitas vezes esses esquemas têm antes o intuito motivacional - para que os operários agüentem o tranco de um trabalho mais intensificado, ainda que possa a priori ser mais interessante e diversificado. 
De uma certa forma, o grosso das empresas brasileiras parece estar aqui. É preciso deixar claro que estar classificado aqui não significa imobilismo, há mudanças concretas no trabalho, quanto pode haver na organização da produção rumo a processos (como em células de produção e/ou esquemas just in time), nas políticas de recursos humanos, e em aspectos de gestão (especialmente com gestão de rotinas e do regime de exploração corrente - ou seja, sem a produção de inovações de produto ou processo - possibilitadas pelas técnicas de "qualidade total", particularmente ao definir clientes internos) etc. Mas não são grandes rupturas, não rompem frontalmente com a lógica de intensificação do trabalho, com a lógica de gerenciar a eficiência da produção via maximização da taxa de produção por hora-homem ("vazão").

Novamente: não se trata de um juízo de valor, de dizer que uma mudança é, do ponto de vista das lógicas de eficiência produtiva prevalecentes no Brasil (ou de qualquer outro ponto de vista), melhor do que a outra. Não é esta a discussão que pretendemos fazer, mesmo porque, dentro do âmbito de "tarefa" há abordagens inovadoras, como pode ser o caso do JIT, TQC/TQM, da análise da produção via "mecanismo da função produção" de Shingo, da manufatura celular etc, que efetivamente significam mudanças; buscamos apenas caracterizar as diferentes mudanças sob um corte metodológico bem definido (o conceito clássico de tarefa).

\section{Mudanças que contestam o conceito de tarefa}

Neste caso, a lógica da organização muda completamente, como muda também o papel operário. A organização não é projetada por "operações" associadas a tarefas, onde se busca o "ótimo" global pela otimização das partes.

Paralelização e segmentação passam a ser conceitos mais importantes do que posto de trabalho. Têm mais relevância a relação entre atividades, do que a atividade em si. Vejamos melhor via um caso de uma empresa radicada no Brasil.

\section{Um Caso Brasileiro de Mudança Radical: O Brasil Também Produz Modelos Organizacionais}

Ultimamente, assiste-se a uma difusão acelerada da idéia de "trabalho em equipe", bastando para tal verificar o número de cursos de treinamento e de seminários sobre o assunto voltados às empresas. "Equipe" ou "grupo" é uma noção problemática: o que define um grupo? Afinal, até os torcedores do Santos Futebol Clube formam um "grupo". As noções de grupo dentro das empresas, por sua vez, também não primam pela homogeneidade e consistência: 
1) Em algumas montadoras (no Brasil e no exterior), cerca de cada dez (ou até mais, conforme a empresa) operários que trabalham na linha de montagem constituem um grupo, que são os fornecedores para o "grupo" seguinte. A lógica geral, aqui, é economizar mão-de-obra, ao buscar contornar os gargalos, sob alegação de que, dentro do grupo, um operário deve ajudar o outro. Esta lógica é bem discutida por Ohno (1988: "0,1 trabalhador ainda é um trabalhador") e Monden (1984). O ritmo pode se intensificar, mas afinal, a taxa de produção por homem-hora é que, efetivamente, é o critério considerado de eficiência produtiva. Este parece ser, junto com o item 2, o "modelo" para empresas de produção discreta em massa, em processos onde o critério básico de eficiência é a taxa de produção horária.

2) Muitas vezes, associa-se "grupo" ao trabalho em células de manufatura, ou ao enriquecimento de cargos, com objetivos semelhantes ao do caso anterior.

3) Mas há casos de grupo efetivamente semi-autônomos, onde a noção de tarefa perde sentido: ao invés da tarefa projetada conforme os ditames clássicos - grosso modo, o caso dos itens 1 e 2 imediatamente acima -, tem-se a discussão de metas e objetivos de um grupo de trabalho, que tem autonomia para se organizar da forma que achar melhor. É fato que há diversas possibilidades e abrangências desse conceito, sendo algumas muito restritivas: por exemplo, quando o trabalho é fortemente submetido ao ritmo do equipamento ou em tempo de ciclo muito curto. Mas é fato, também, que há poucas mas significativas experiências de muito sucesso, como a do caso que ora discutiremos.

\section{A fábrica sem departamentos, o operário-gerente}

Trata-se de uma produtora de produtos químicos sólidos destinados principalmente ao consumidor final (pessoa física). Trabalbando em três turnos, está estruturada em três mini-fábricas, definidas conforme a lógica do processo de transformação:

1) A primeira produz um produto químico que é tanto enviado para outras fábricas quanto para a mini-fábrica 2; trata-se de um processo contínuo em turnos de revezamento, controlado por sistema digital. A equipe de operação é pequena e homogênea, todos são técnicos (nível $2^{\circ}$ grau/Senai), com complemento de formação tanto no processo específico, quanto em outra habilidade, no que é chamado de duplo skill: o técnico em química é treinado em mecânica, o de mecânica em eletricidade, o de eletricidade em eletrônica. $O$ processo é basicamente químico (reação).

2) A segunda processa a matéria-prima que recebe da anterior, sendo que no processo entram inúmeras outras matériàs-primas compradas de terceiros. A equipe de operação é composta de técnicos de processo e técnicos mecânicos, operadores e auxiliares; boa parte do processo apresenta instrumentação e controle digital, mas há também manobras manuais. O processo é uma mistura de processos físico-químicos e mecânicos. 
3) A terceira embala e disponibiliza o produto para almoxarifado e expedição. Há técnicos de embalagem (de perfil mecânico) e ajudantes; as máquinas não são de última geração (poucas possuem controle eletrônico, já disponível para o tipo de processo), e o processo é basicamente de cunho mecânico, sendo que a eficiência é derivada basicamente do ajuste fino do equipamento, o que minimiza paradas e perdas de material.

Há um gerente-geral e um gerente por mini-fábrica. Não há nível hierárquico entre estes últimos e os operários.

Nas duas primeiras mini-fábricas, além de não haver supervisão, não há mão-de-obra indireta, seja de manutenção ou controle de qualidade: há um gerente em horário comercial, e os operários 24 horas. Isso significa que, na maior parte das horas trabalhadas, só há operários, que respondem pela fábrica, e operam equipamentos de dezenas de milhares de dólares, sendo responsáveis coletivamente pela qualidade, pela manutenção, pelo recebimento de materiais e pelo fornecimento aos clientes, sejam internos ou externos. Dentro de cada mini-fábrica, não há funções pré-definidas; os operários realizam reuniões e definem como vai ser a alocação em função do desenrolar dos eventos da produção. Obviamente, há uma liderança por parte dos técnicos nas mini-fábricas 1 e 2 , dado seu conhecimento do processo, mas não há subordinação hierárquica.

Há um serviço de manutenção geral bastante reduzido, que trabalha sob plano (preventivo/preditivo) ou chamada. Qualquer pessoa da fábrica pode abrir ordem de serviço de manutenção, não é preciso autorização. Não há máquinas na manutenção (torno, fresa etc.); se, por exemplo, um eixo quebrar às $03: 00 \mathrm{~h} \mathrm{da}$ madrugada, o técnico que diagnosticar telefona para uma empresa de usinagem pré-contratada, telefona para um serviço de taxi pré-contratado, que apanha a peça e a leva para ser usinada.

Os operários das mini-fábricas possuem um orçamento que podem manipular, de cerca de US $\$ 100,00 /$ mês. Em entrevista com o gerente-geral, perguntamos como tal valor foi dimensionado, e qual sua lógica. A resposta foi cristalina: se se quer estimular a responsabilidade, se a fábrica fica "na mão" dos operários, eles devem ter alguma autonomia orçamentária também; o valor foi "chutado", não era a variável relevante - com ele, os grupos compram reagentes de laboratório, material de escritório etc.

Os grupos são abertos, isto é, sua composição varia conforme o turno, e dentro do turno conforme a necessidade. Mais rigorosamente, os grupos se constituem a partir dos eventos que ocorrem na produção, ou daquilo que têm que tratar (ZARIFIAN, 1995). Por exemplo, assistimos a uma reunião de um grupo-tarefa de confiabilidade de um determinado equipamento, que vinha apresentando problema crônico. Para a reunião foram chamadas as pessoas envolvidas: o gerente da área, um auxiliar que lida diretamente com o equipamento, um técnico que trabalha na área, engenheiro 
de projeto, técnicos de manutenção. Para que tal reunião ocorra, os operários que continuam na produção precisam reconhecer a importância de que um companheiro de seu grupo se ausente, porque o que está em jogo é a eficiência global do sistema; é preciso, também, que os diversos saberes profissionais não só dialoguem, mas que reconheçam mutuamente sua importância. Isto não se consegue com apelos fáceis para que se "vista a camisa" da empresa, ou com um sistema formal de informações, computadorizado ou não: faz-se necessário o que Veltz e Zarifian (1994) chamam de processo comunicacional aberto, envolvendo sobretudo aspectos respectivamente normativos (validação social das normas e objetivos da produção) e cognitivos.

Dentro desse processo de comunicação, de validação normativa e cognitiva, realizam-se uma série de reuniões entre operários $^{8}$. Semanalmente, há uma reunião de planejamento, onde os grupos que estão trabalhando naquele dia (conhece-se a escala com antecedência) enviam representantes; discute-se a programação da produção com os planejadores, os problemas das áreas produtivas e administrativas com os gerentes e o pessoal das áreas, e até o cardápio do restaurante.

A flexibilidade não é apenas da produção, mas a própria estrutura organizacional é mudada sem grandes sobressaltos. Por exemplo, foi sugerido e adotado que um técnico de cada mini-fábrica passasse a trabalhar, em sistema de rodízio, no horário administrativo, para encaminhar questões que sobrecarregavam o trabalho cotidiano. Quando há problema, os técnicos, operadores ou ajudantes de uma mini-fábrica se ajeitam entre si para auxiliarem seus companheiros de outra mini-fábrica. Numa certa época, os gerentes (incluindo os não vinculados à produção) resolveram rodar turnos, pois havia alguns problemas produtivos. Numa outra época, os coordenadores da embalagem deixaram de rodar turnos; depois, voltaram a rodar turno; depois, foram requisitados temporariamente supervisores de outra fábrica da Companhia, para que ajudassem, com sủa experiência, na estabilização de um processo. $\mathrm{O}$ operário hoje está numa máquina, mas amanhã poderá estar sentado com o gerente-geral discutindo problemas de produção: é operário, mas também é um pouco gerente - o caso a seguir exemplifica ainda mais.

Os operários da mini-fábrica 1 perceberam um problema no processo, que para ser solucionado significaria a parada do processo. A decisão era: para-se o processo e acerta-se já o processo, ou se espera mais um pouco? Para tomar essa decisão, seria preciso saber qual o cronograma real de necessidades dos clientes ${ }^{9}$ : os operários fizeram um levantamento do nível dos estoques, examinaram a programação da produção $e$ o cronograma de expedição, telefonaram para o cliente externo, perguntando se ele teria efetivamente necessidade de receber aquela partida na data prevista; como foi constatado que o nível dos estoques dos clientes interno e externo eram suficientes, 
os operários decidiram parar o processo, acertando o equipamento.

Tivemos a oportunidade de realizar, nesta empresa, uma dinâmica especial com operários $^{10}$ : via colagem, discutimos o esquema de trabalho em grupo com os operários. Muitas reclamações, muitos problemas, mas uma unanimidade: é muito melhor trabalhar dessa forma, ainda que se trabalhe mais.

É claro que nem tudo são flores nesta fábrica. Nesta breve descrição, procuramos apenas caracterizar que existe a possibilidade de esquemas organizacionais inovadores em essência no Brasil - e muita gente vem de fora para conhecer tal fábrica, que tem um excelente padrão de desempenho dentro de suas congêneres.

\section{Conclusões: Será Que Há Alguma?}

A reestruturação produtiva é extremamente desigual e contraditória. Muita pesquisa precisa ser feita para que se estabeleça uma visão um pouco mais abrangente, e que dê conta da diversidade. É preciso cuidado, contudo, ao tratar qualquer mudança como "ruptura de paradigmas". Antes, é preciso caracterizar muito bem do que se está falando: a lógica da organização do trabalho não é necessariamente a lógica da organização da produção; mudanças no trabalho podem não significar mudanças de fundo na lógica em torno da qual se estrutura a produção, sua gestão, seus indicadores de eficiência.

\section{Notas}

1. De uma forma genérica, a busca de conseguir o controle da produção e comercialização de um produto com investimento relativamente mais baixo. Por exemplo, a fábrica analisada no item 4 custou cerca de $35 \%$ menos do que a fábrica similar anterior da companhia (mesmos produtos), e tem capacidade produtiva $150 \%$ maior; o mesmo pode ser dito da nova fábrica de caminhões dã VW, na qual parte substancial do investimento necessário está sendo arcado por um seleto grupo de fornecedores. Isto, porém, não significa necessariamente desconcentração do capital; os indícios, inclusive, vão na direção oposta.

2. O exemplo da "falange" de Alexandre é didático, não só por estar nos livros de história. $\mathrm{O}$ exército era organizado em camadas sucessivas de soldados; a primeira camada portava escudos e espadas curtas; a segunda camada, imediatamente sucessiva, portava espadas mais compridas, e assim por diante. $O$ resultado era que o inimigo via-se defronte a uma "parede" de espadas, pois o artefato era projetado de acordo com a organização pretendida, e não o contrário.

3. "A idéia de tarefa é, quiçá, o mais importante elemento na administração científica. O trabalho de cada operário é completamente planejađo pela direção, pelo menos, com um dia de antecedência e cada homem recebe, na maioria dos casos, instruções escritas completas que minudenciam a tarefa de que é encarregado e também os meios usados para 
realizá-la. (...) Na tarefa é especificado o que deve ser feito e também como fazê-lo, além do tempo exato concebido para a execução. (...) A administração científica, em grande parte, consiste em preparar e fazer executar essas tarefas" (Taylor, 1978:51).

4. O problema básico da manufatura inglesa da época de Adam Smith parecia ser outro, qual seja, a redução da massa salarial; os "princípios econômicos da divisão do trabalho" enunciados por Charles Babbage estão intimamente ligados à idéia de se adquirir apenas a competência necessária para a realização de um determinado trabalho - um oficial sapateiro deve se concentrar em cortar o couro e não em embalar os sapatos prontos, pois esta última atividade pode ser desempenhada por trabalhadores de menor salário. A eficiência, por sua vez, é atribuída à repetitividade do trabalho, mas não há uma abordagem sistemática sobre os tempos na produção, como propõe Taylor e "correligionários" (Gantt, Gilberth, Ford etc).

5. Mas também, em menor grau nas fábricas da Coca-Cola em Jundiaí e na remodelação da Ford em São Bernard.

6. Não há prescrição maior de tarefa do que aquela via linha de montagem: a tarefa está cristalizada no posto e na velocidade da linha; o método está pré-definido, por mais que os montadores possam "cooperar" entre si. Parker e Slaughter (1988) fazem uma análise bastante desmistificadora de tal tipo de "inovação", que grassa na indústria automobilística mundial e mesmo nas fábricas radicadas no Brasil.

7. A bem da verdade, a questão de trabalho em grupo é muito mais complexa. Exige uma nova abordagem em termos de projeto organizacional, abordagem que não está muito bem estabelecida na literatura pertinente: uma análise ligeira parece mostrar que a maioria dos inúmeros livros e artigos sobre o trabalho em grupo é de cunho comportamental, escrita por psicólogos; pouco há em termos efetivos de projeto organizacional - a própria literatura sócio-técnica, à qual é atribuído o conceito de grupo semi-autônomo, pouco aborda os aspectos de projeto. Há algum movimento nesse sentido: pesquisas do LATTS/ENPC, texto de Sitter, Dankbaar e Hertog (1994), e pesquisa que ora estamos desenvolvendo, bem como outros colegas de nosso grupo de pesquisa (vide uma primeira abordagem em Salerno, 1994).

8. Há as de rotina, como a de troca de turnos, que tem uma superposição de 30 minutos projetada especialmente para viabilizá-la; há as extraordinárias, convocadas pelos próprios operários.

9. No caso, a mini-fábrica 2 e um cliente externo, que compra o produto para processá-lo.

10. Em conjunto com Luiz Felipe Cortoni. O mesmo foi feito em outras três empresas. 


\section{Referências Bibliográficas}

HIRATA, H. Sobre o modelo japonês. São Paulo, EDUSP, 1994.

MONDEN, Y. Produção sem estoques. São Paulo, IMAM, 1984.

OHNO, T. Toyota production system: beyond large-scale production. Cambridge, Productivity, 1988.

PARKER, M; SLAUGHTER, J. Choosing sides: unions and team concept. Boston, Labor Notes/South End, 1988.

SALERNO, M. S. Trabalho em grupo semi-autônomo: uma análise dos problemas de concepção e implantação. In: Workshop Internacional para Onde Caminham as Organizações, São Paulo, 18-9 ago. 1994. Anais. São Paulo, EPUSP/DEP, 1994. p.39-49.

SHIMIZU, K. Kaizen et gestion du travail chez Toyota Motor et Toyota Kyushu. In: Second GERPISA International Colloquium The New Industrial Models of Automobile Firms, Paris, 1994. Anais. Paris, GERPISA, 1994 /Faculté des Sciences Economiques, Université de Okayamal

SITTER, L.U.; DANKBAAR, B.; HERTOG, J.F. Designining simple organisations and complex jobs. Maastricht, Maastricht Economic Research Institute on Innovation and Technology , 1994. (MERIT RM2/94-012)
TAYLOR, F. W. Princípios de administração científica. 7.ed., São Paulo, Atlas, 1978.

VELTZ, P; ZARIFIAN, P. Vers de nouveaux modèles d'organisation? Sociologie du travail, v.XXXV, n.1, 1993, p.3-25.

ZARIFIAN, P. La nouvelle productivité. Paris, L'Harmattan, 1990. Le travail et l'événement. Paris, L'Harmattan, 1995. 